\title{
Pseudo-intertextualidade: e a história, não é uma construção?
}

Denize Correa Araujo 


\section{Resumo}

Este ensaio analisa em particular o longa Watermelon Woman, de Cheryl Dunye, tentando contextualizá-lo no cenário dos Estudos Culturais Norte-Americanos, como inovador e transgressor tanto em técnica quanto em estética. Dunye propõe uma série de reflexões sobre temas como lesbianismo e racismo, implicitando seus conceitos estéticos, que levam a questionamentos que transcendem questões de ordem política ou social. O filme provocou as mais diversas reações no Congresso e ganhou o "Teddy Bear" no Festival de Berlim. Com o lema "precisamos fazer nossa própria história", Dunye desafia os limites já tênues entre ficção e não-ficção, usando recursos metalingüísticos para colocar em pauta não só temas de gênero e raça como também uma proposta que provoca uma reflexão sobre a linguagem cinematográfica em relação ao passado histórico e ao ato de construir uma história.

\section{Palavras-chave}

pós-colonialismo, estudos culturais, estudos de gênero

\section{Abstract}

This essay analyzes, among other issues and more specifically, "Watermelon Woman", a film by Cheryl Dunye, trying to contextualize it within the scenery of American Cultural Studies as innovator and transgressor in techniques as well as in aesthetics. Dunye proposes a series of reflections about themes as lesbianism and racism, implying her aesthetic concepts to question issues that go beyond social or political realms. The film provoked the most varied reactions at US Congress and won the "Teddy Bear" in the Berlin Festival. Stating that "we have to build our own history", Dunye defies the already thin limits between fiction and non-fiction, using metalinguistic devices to deal with gender and race while proposing a new perspective on film approaches in the interactive process of constructing the historical past and inventing a story.

\section{Key words}

postcolonialism, cultural studies, gender studies 
tuart Hall, em seu ensaio Cultural Studies and its Theoretical Legacies (Estudos Culturais e seus Legados Teóricos), discute as discrepâncias entre teoria e prática na área de estudos culturais. De acordo com o autor, o campo se tornou popular nos Estados Unidos e sua inclusão nos estudos acadêmicos universitários é a vitória de um objeto de estudo privilegiado: cultura, ideologia, linguagem, o simbólico (279-283). Para Hall, o campo deve manter um comprometimento político expresso tanto teoricamente como em prática.

O ponto de controvérsia desse debate é a reflexão sobre até que ponto a proposta de estudos culturais pode ir sem enfatizar mais uma luta política por uma causa em detrimento de um movimento estético. Apesar de ser sem dúvida muito complicado conseguir uma interação balanceada entre política e estética, é este o mérito da videomaker Cheryl Dunye. Ao mesmo tempo em que questiona gênero e raça, o texto revela um enredo artístico com recursos intertextuais que propiciam uma interação entre a proposta política e a estética.

Trabalhando polissemicamente, o texto é uma série de fragmentos divididos em tempo e espaço referenciais, uma alusão à cinematografia antes do advento do som. Seu enredo digressivo se desenvolve rizomaticamente (Deleuze e Guattari, 2000), como um tex to em construção, filmado como se não seguisse roteiro, como se estivesse sendo construído a cada nova cena, como se cada cena não prevista desencadeasse outras também espontâneas. A metalinguagem em diversos níveis incentiva a interação dos espectadores a uma possível procura, a mesma das protagonistas, que bus- 
cam encontrar uma atriz afro-americana supostamente lésbica. A interação do espectador é na verdade outro recurso para o desenvolvimento da trama.

A simples pergunta "sobre o que é o filme?" permite desde uma resposta simplista até um discurso elaborado. Se analisado dentro dos parâmetros tradicionais, o texto pode ser considerado "amador", não bem-acabado. Apesar disso ou por causa disso, se os mesmos elementos forem considerados intencionais, The Watermelon Womain (WW) ${ }^{1}$ pode ilustrar o aspecto positivo das narrativas fragmentadas, do desaparecimento das fronteiras entre "alta e baixa cultura", e da auto-crítica paródica implícita em relação aos aspectos de gênero e raça abordados no texto.

Longe do tom de auto-comiseração empregado por alguns textos que têm por tema as minorias, a videomaker evita os clichês de acoitadamento e de agressão contra opressores, o que quase sempre contribui para perpetuar os estereótipos. O texto descentra 0 relacionamento homossexual entre as raças branca e negra, e parodia o tratamento melodramático frequientemente dado ao tema.

Descentramento talvez não seja o termo adequado, considerando que implicaria em mudança de um centro a outro, o que não alteraria muito o processo. No caso de "WW", pode-se dizer que há um "acentramento", fazendo desaparecer qualquer posição hierárquica que porventura ainda existisse.

Antes de prosseguir na análise, porém, é preciso estabelecer certos links entre pós-colonialismo e pós-modernismo, entre estudos culturais e estética. De acordo com Gayatri Spivak (1988), há uma afinidade entre o sujeito imperialista e o sujeito do humanismo (p. 202). O sujeito imperialista é o objeto da crítica do pós-colonialismo ao passo que o pós-modernismo tem como objeto de crítica o sujeito do humanismo, apesar de que em ambos os casos o que o feminismo critica é o aspecto patriarcal envolvido nos dois lados da discussão. O problema central parece ser o que Linda Hutcheon (1989) observa: a ordem dominante pode se dar ao luxo de desafiar o que ela possui com segurança (p. 151).

1. Usarei "WW" algumas vezes, para evitar repetições constantes; 
Mesmo quando o dominante está aparentemente interessado na cultura dominada, a preocupação não tem origem em base sólida. $\mathrm{O}$ interesse que as maiorias têm pelas minorias é quase sempre deformado. A protagonista de "WW" não gosta de pensar que afro-americanos devem ter relações só com parceiros da mesma raça, partindo da premissa de que a raça é mais importante do que a pessoa. $\mathrm{O}$ mesmo argumento foi problematizado no filme brasileiro Cruz e Sousa, de Sylvio Back, onde o poeta negro se relaciona com mulheres brancas, causando acusações ao diretor. No filme de Victor Masayesva Imagining Indians, o diretor mostra como certos objetos indígenas são comprados e usados para decoração, sem que nenhum respeito pelo seu simbolismo seja demonstrado. Com a desculpa que "são tão exóticos que não pudemos resistir", ou "fazemos os índios tão felizes se comprarmos seus objetos", o interesse demonstrado quase sempre é mal dirigido. Linda Hutcheon (1989) expressa sua preocupação em relação às estratégias colonizadoras de dominação e questiona o ponto preciso em que interesse e preocupação se tornam apropriação imperialista (p. 154). Alguns críticos pós-colonialistas, como Cornel West, consideram o pós-modernismo um discurso imperialista: a maioria das reflexões do Primeiro Mundo sobre o pós-modernismo permanecem bastante regionais e provincianas, quer dizer, profundamente eurocêntricas (West, 1989, p. 87).

Estudos críticos do Primeiro em relação ao Terceiro Mundo, como também sobre as minorias, podem cair na mesma falácia de estudar o "exótico" para seus próprios propósitos, que certas vezes não são relevantes. Os dois problemas mais sérios parecem ser a apropriação de assuntos relacionados às minorias, seja para domesticá-los e analisá-los de acordo com um ponto de vista imperialista, ou para reduzi-los a classificações que não levam em conta suas características específicas. Ambos os procedimentos podem contribuir para representações estereotipadas e para uma redução na apreensão da complexidade dos temas.

Os textos Watermelon Woman e Imagining Indians evitam a domesticação de seus temas e a redução de suas potencialidades. Pelo contrário, ambos denunciam os estereótipos hollywoodianos e os falsos interesses demonstrados pelas respectivas culturas, a afro-americana e a nativa-americana. 
Quanto à problemática "estudos culturais x estética", os pontos de vista variam. A maioria dos críticos concorda que estudos culturais devem estar comprometidos com agendas políticas e devem ser um discurso de resistência. A tentativa de por a teoria em prática, porém, é freqüentemente levada ao extremo e suas conseqüências radicais podem obliterar a estética em favor de técnicas de poder e persuasão.

James Soderholm, em Beauty and the Critic: Aesthetics in an Age of Cultural Studies, apresenta uma compilação de artigos que tratam exatamente da tentativa de relegar a estética a um segundo plano para melhor focalizar o discurso político. Christopher Beach (1997), em seu artigo "Recuperating the Aesthetic", apresenta uma versão antagônica:

Apesar das recentes tentativas de exilar o estético do mundo da literaturalestudos culturais, o estético não será facilmente eliminado ou isolado: as questões relativas à natureza e papel do estético teimosamente persistem no nosso discurso entre literatura e cultura (p. 96).

Os textos de Masayesva e Dunye têm mais esse ponto comum. Ambos se preocupam com a estética acima de tudo, considerando que é através do enfoque artístico que são discutidas questões relativas a aspectos raciais e de gênero.

"WW" não evita assuntos problemáticos. Ao contrário, revela as injustiças do sistema social sem apontar explicitamente e sem fazer desse discurso o ponto central, o que infalivelmente levaria o texto a um objetivo político muitas vezes desprovido de elementos artísticos.

A procura da atriz conhecida por "mulher melancia" serve como pretexto para a montagem do filme. A série de entrevistas remete a Cidadão Kane, no qual reporteres e jornalistas arduamente procuram o significado da última palavra do protagonista, rosebud (botão de rosa), balbuciada antes de sua morte. Adicionando outra dimensão ao seu texto, a videomaker faz com que a protagonista (ela mesma) parodie a escrava, um recurso para desmistificar o 
melodrama produzido por aquela antiga categoria de filme. A estrutura de encaixe, ou seja, o filme-dentro-do-filme, é mostrada em preto e branco e serve para remontar a carreira da atriz, cujas preferências sexuais parecem coincidir com as da protagonista que, por sua vez, é representada por Cheryl, a diretora do filme.

Buscando levantar fatos sobre a vida de uma atriz inventada, no texto interno, a videomaker coleta depoimentos que desvelam os preconceitos raciais e sexistas através da trama ficcional que se assemelha à sua e que interage com o texto externo. O mesmo recurso artístico é usado no filme mexicano Bienvenido Welcome, de Gabriel Retes, no qual o tema da Aids é retratado no filme-dentro-do-filme.

Enquanto a tendência de tratar gender issues (assuntos de gênero) em textos contemporâneos parece ser muito agressiva, política e explícita, no texto de Dunye a relação homossexual é tratada como qualquer outra e seus problemas não são específicos e sim os mesmos que culminam com o fim de muitas relações. Quando o relacionamento se acaba, as razões podem ser inúmeras, incluindo o fato de que Diana, branca, rica e mimada, talvez esteja interessada em ter relações só com mulheres de cor, o que resultaria em um caso de objetivação. Um ponto de interesse é que Dunye "descobre" que Fae Richards, a "mulher melancia", teve um caso com uma branca, diretora de filmes. Com isso, pode-se aventar uma hipótese de que seu texto-dentro-do-texto seja um reflexo de seus sentimentos inconscientes sobre relações birraciais.

Sua escolha do recurso de mise en abîme sutilmente chama a atenção para o texto principal. Um texto interno colocado 'en abîme' tem o poder de fazer com que o texto externo pareça real, especialmente se a artificialidade do texto interno for enfatizada (Holman; Harmon, 1986, p. 296). Esse é o caso da passagem relativa à relação da "mulher melancia" com a rica diretora branca. A impressão é que o intertexto é ficcional e o texto externo é "real".

Andrea Stuart (1997), resenhando o filme, critica veementemente o texto de Dunye:

O poder do filme está no desejo do espectador em saber a história da mulher melancia, uma atriz negra lésbica 
dos anos 30, que nunca existiu. A justificativa de Dunye para sua estratégia, "precisamos construir nossa própria história”, não é suficiente. No final das contas, a invenção pode justificar e obliterar o passado? A impressão é que Dunye está esquecendo das complexidades e contradições que nunca poderiam ser eliminadas na vida real. (p. 64)

Talvez o problema desse tipo de crítica é que Stuart classifica o filme de satimentary, um documentário-sátira, o que não parece ser a proposta do filme que é, sem dúvida, uma mistura de ficção e nãoficção. Se levarmos esse fato em consideração, qual a razão para cobrar da diretora um compromisso com fatos? E que são "fatos"? É exatamente a inventividade da trama que dá ao filme a dimensão estética auto-reflexiva. Hutcheon (1989), em seu ensaio, Circling the Downspout of Empire, explica que a arquitetura foi a primeira a usar o termo "pós-moderno" às formas estéticas, acrescentando que

estendendo a definição para outras formas de arte, o termo 'pós-moderno' pode então ser usado, por analogia, para descrever a arte que é, paradoxicalmente autoreflexiva (em relação à técnica e material) e mesmo assim embasada em realidade política e histórica (p. 150).

O fato de que "WW" é uma invenção não invalida os inegáveis eventos da História Afro-Americana nem elimina os preconceitos sofridos pelas lésbicas. Janet Abu-Lughod (1989), em seu ensaio On the Remaking of History: How to Reinvent the Past, sugere que ao mesmo tempo que é verdade que inventamos a História, como Marx já dizia, não temos latitude tão arbitrária e tão ampla para fazermos o que queremos (pp. 126-127). A estratégia que Dunye usa, brilhantemente inventando uma atriz lésbica negra, é tão plausível que os espectadores só percebem que é invenção quando a diretora anuncia isso no final do filme.

A pseudo-intertextualidade que, de acordo com Plett (1991, p. 20), é uma intertextualidade que se refere a um texto inexistente, 
oferece aos espectadores a distância necessária dos assuntos problematizados e lhes permite liberdade para pensar e decidir por eles mesmos, ao invés de sofrer imposições, o que acontece com muitos textos de crítica pós-colonialista.

A escolha do elenco e a maneira de filmar empregada por Dunye em "WW" relembram o Neo Realismo Italiano, o Cinema Novo e mais recentemente o Dogma, três momentos onde os atores não são profissionais e onde as locações são "reais". Para enfatizar a "autenticidade", há referências específicas de tempo e espaço nas entrevistas. Portanto, se por um lado o filme pode ser classificado como documentário, por outro não podemos esquecer que se refere a um pseudo-texto, não podendo ser mais ficcional. Dunye explica ambos os lados: Sou uma história também. Sou um tema válido. Não acho que deva procurar outro tema quando tenho a história em minhas mãos e esta história nunca foi contada antes (Kim, 1991, p. 860). Acrescenta que embora certas partes do texto são verdadeiras, ela não encontrou nenhuma informação sobre lésbicas afro-americanas na História do Cinema. Como não estava acontecendo, inventei (Stockell, 1996, p. 69).

Essa mistura de gênero é outro resultado dos intertextos. Vivendo no intermezzo (Deleuze e Guattari, 2000) da ficção e não-ficção, o texto constrói um artefato dentro de um artefato. O pseudo texto aborda o tema da escravidão, sem contudo fazê-lo o centro do filme. O texto principal aborda o tema do lesbianismo, também sem torná-lo central².

Acentrado, o filme é auto-reflexivo e questiona o que é o cinema, quem foi a "mulher melancia", qual a relação entre o filmedentro-do-filme com o outro. Parece que a câmera vai à procura de respostas, que ao mesmo tempo não são satisfatórias ou não são tão importantes como a procura em si, que vai formando uma coleção de fragmentos.

2. Durante uma entrevista, Dunye disse que prefere não colocar a sexualidade como o mais importante atributo: Não quero supervalorizar a sexualidade ou acender holofotes sobre isto. A sexualidade é grande parte do que somos, mas não é tudo que fazemos. Muitas de nós são ativistas, outras ainda enrustidas. Somos trabalhadoras e plantadoras (Kim, 1991, p. 87); 
Fazendo uma colagem de textos com referências temporais e espaciais (para comprovar a autenticidade) a um intertexto construído, o filme questiona o que é a representação. Como Chinua Achebe explica: Devemos estar preparados para aceitar o fato de que a representação é eo ipso, implicada, interrompida, interrelacionada, embutida, entrelaçada com muitas outras coisas ao lado da 'verdade', o que também é uma representação (Childs e Williams, 1997, p. 105).

É verdade que as mulheres têm que negociar com o patriarcado. É também verdade que as mulheres negras tiveram que lutar muito para serem representadas em bibliografias. Além disso, ninguém pode negar que a escravidão ainda existe em diversas maneiras. O tema da representação em ficção, porém, não tem necessidade de ser tão brusco nem tão monológico quanto pode ser em realidade. Em "WW", há muitas representações de personagens femininos. Evitando uma visão radical, Dunye oferece diversos tipos de mulheres como numa montagem palimpsesta. Ela mesma é a diretora, a atriz, a versão paródica da "mulher melancia", e a camerawoman. Alem disso, ela se apresenta no filme exatamente assim, enfatizando o "como se representa" e, assim, problematizando os conceitos de referencialidade e representação.

Dunye está interessada em negociar posições mas evita escolhas simplistas. Ela não procura "representar" a lésbica, ou a negra, ou a cineasta num ambiente hostil como parte de um compromisso político que pressupõe uma posição de resistência ou denúncia. Seu esforço é no sentido de problematizar a representação, provocando reflexões: deveria a escrava ser romantizada? Deveria a companheira da protagonista ser um exemplo de perfeição? Deveria o relacionamento ter um final feliz? Como as entrevistas deveriam ser filmadas?

Privilegiando uma sequiência rizomática de fragmentos, Dunye evita o esquema "arbóreo" (descrito por Deleuze-Guattari em oposição ao rizoma), e opta por construir um passado, criando uma História sem submissão aos seus estereótipos. No passado, o conceito de raça sofreu muitas mudanças. Antes de 1400, servia para denominar a raça humana de maneira geral. A ideologia racista, no século XVI, 
foi justificativa para a escravidão no Novo Mundo. Estudos contemporâneos têm revivido o conceito, mas em muitas ocasiões os esforços para redimir o passado ou esquecê-lo resultam em interpretações que podem fossilizar estereótipos ou romanceá-los. Como Aldon L. Nielsen (1994) comenta:

se leituras passadas apelam positivamente para a presença racial, para um ponto de referência extra sistêmico numa subjetividade racial estável, seja do autor ou do leitor, uma leitura intertextual pode descobrir significado no jogo das diferenças (p. 22).

Em "WW", o conceito de passado é cuidadosamente elaborado, e fica melhor entendido se contextualizado em um cenário que distingue a história oficial da memória popular. Teshome Gabriel (1989) sugere que a história oficial tende a aprisionar o futuro por meio do passado. Segundo o crítico e teórico pós-colonialista, historiadores privilegiam a palavra escrita do texto, servindo-se dela como norma de lei e enfatizando um "centro" que continuamente marginaliza os outros. Essa ideologia faz com que muitos se sintam inibidos para a construção de suas próprias histórias. A memória popular, por outro lado, continua Gabriel, considera o passado como um assunto político, um ponto de referência. A memória popular não é uma volta a uma tradição gloriosa nem um vôo a uma imaginária "torre de marfim", não é um escapismo auto-indulgente nem um desejo da experiência e do conteúdo do passado por ele mesmo. Em vez disso, é um olhar "de volta ao futuro", sempre com possíveis mudanças.

Se Dunye procura por um personagem ficcional, este personagem poderia ter existido, se considerarmos os fatos históricos. Por outro lado, o tratamento irônico dado ao personagem que Fae Richards representa, uma black Mammy ${ }^{3}$, permite interpretá-lo como recurso retórico. Hutcheon (1989) sugere que

3. Carol Allen, em seu livro Black Women Intellectuals, explica que há dois estereótipos de mulheres negras, a "Mammy" (ama que amamentava crianças brancas), considerada "boa" e a "Jezebel", figura sexual, considerada "má". 
a ironia se torna uma estratégia popular retórica para trabalhar entre discursos existentes e testá-los ao mesmo tempo. Sua duplicidade semântica e estrutural pode se constituir em tropo para as dualidades paradoxais de ambos, a crítica cúmplice pós-moderna e a dupla história e identidade pós-coloniais. E de fato a ironia se tornou uma ferramenta subversiva poderosa no repensar e re-endereçar da história por artistas pós-modernos e pós-coloniais. (p. 154)

O que está em jogo, então, quando o filme-dentro-do-filme reflete os temas que o filme pretende endereçar? O termo mise en abyme realmente significa "colocado no abismo", uma imagem autoreferencial espelhada novamente em versão menor, como se pudesse ser vista duplamente, mas não com a mesma clareza como se fosse vista somente uma vez, visto que a dualidade pode também levar à ambigüidade e ambivalência. Será que a relação que a "mulher melancia" desenvolve com a diretora branca tem algo a ver com o romance de Cheryl e Diana? Pode o intertexto ser mais forte do que o texto? Será que a auto-reflexão ajuda a representação de assuntos polêmicos?

Se o pseudo texto é uma tentativa de encontrar respostas que não podem ser encontradas no texto, este, por sua vez, será uma tentativa de achar uma solução que não pode ser encontrada na vida real? Estas multiplicidades criadas pelo processo de mise en abyme dão origem a outras reflexões: estará a cineasta implicitando que as relações birraciais são mais fáceis agora do que eram no passado? Estará ela dando uma dimensão histórica ao texto? Ou estará ela sugerindo que no cenário contemporâneo as atitudes ainda são problemáticas?

Parece que Dunye não quer responder a essas questões e sim sugerir o debate. Através de sua cuidadosa jornada, a videomaker, que é também negra e lésbica, remonta a memória coletiva e conduz entrevistas fictícias, construindo uma "naturalidade" que parece ser espontânea. De fato, o ponto de interesse na narrativa é que a "criação" de Dunye parece natural, visto que o estereótipo da escrava negra se tornou facilmente assimilável no cinema hollywoodiano, onde 
os personagens negros são parodiados, ironizados ou explorados sexualmente, como objetos exóticos.

Usando o filme como mídia para expressar suas preocupações sobre raça e gênero, e mostrando-o esteticamente, Dunye parece concordar com Gutierrez Alea quando este diz:

... se queremos que um filme sirva como algo mais alto, se queremos que desempenhe sua função mais perfeitamente (estética, social, ética e revolucionária), teremos que garantir que se constitua um fator de desenvolvimento do espectador. Um filme será tanto mais frutífero quanto mais levar o espectador a um entendimento profundo da realidade, conseqüentemente, a ponto de ajudar os espectadores a viver mais ativamente $e$ incitá-los para que deixem de ser meros espectadores frente à realidade. Para fazer isso, um filme tem que apelar não só para a emoção e sentimento mas também à razão e ao intelecto... (1982, p. 21)

O filme "WW" sem dúvida tem um mérito inegável: provocou enorme polêmica no Congresso, onde os republicanos conservadores alegaram que o dinheiro de taxas pagas pelo povo não deveria ser usado para mostrar tais abusos comportamentais (Dunye recebeu 31.500 dólares do NEA, National Endowment for the Arts). Por outro lado, o filme ganhou o "Teddy Bear" no Festival de Berlim de 1996, e foi um dos objetos de crítica quanto aos critérios adotados para julgamento. De fato, nem o eurocentrismo nem os parâmetros hollywoodianos parecem ser critérios adequados para a produção independente e alternativa. 


\section{Bibliografia}

ABU-LUGHOD, Janet.1989. "On the Remaking of History: How to Reinvent the Past". In: Remaking History. Ed. Barbara Kruger e Phil Mariani. Seattle: Bay Press, 111-129.

ALEA, Tomás Gutiérrez. 1982. Dialéctica del Espectador. La Habana: Ediciones Union.

ALLEN, Carol. 1998. Black Women Intellectuals. NY: Garland Publ.

BEACH, Christopher. 1997. "Recuperating the Aesthetic: Contemporary Approaches and The Case of Adorno". In: Beauty and the Critic: Aesthetics in an Age of Cultural Studies. Ed. James Soderholm. Tuscaloosa: U Alabama P, 94-112.

CHILDS, Peter; WILLIAMS Patrick. 1997. An Introduction to PostColonial Theory. London: Prentice Hall.

DELEUZE, Gilles; GUATTARI, Félix. 2000. Mil Platôs. RJ: Ed. 34.

DUNYE, Cheryl (dir.). 1997. The Watermelon Woman. Cheryl Dunye e Dancing Girl Prod. Inc.

FREEDMAN, Allan. 1997. "Replaying the Battle Scene over NEA Funding". Congressional Quarterly Weekly Report, 55.11 (Mar. 15), pp. 624-626.

GABRIEL, Teshome H. 1989. "Third Cinema as Guardian of Popular Memory: Towards a Third Aesthetics". In: Questions of Third Cinema. Ed. Jim Pines e Paul Willemen. London: BFI, pp. 53-64.

HALL, Stuart. "Cultural Studies and its Theoretical Legacies". In: Cultural Studies. Ed. Lawrence Grossberg, Cary Nelson e Paula Treichler. NY: Routledge, pp. 277-294.

HOLMAN, C. Hugh; HARMON, William.1986. A Handbook to Literature. NY: Macmillan Publ. Co., 1986.

HORTON, Andrew; MCDOUGAL, Stuart Y. 1998. Eds: Play it Again, Sam: Retakes on Remakes. Berkeley: U of California P.

HUTCHEON, Linda. 1989. "Circling the Downspout of Empire". In: Ariel 20.4. Oct., pp. 149-175.

KIM, Lorrie. 1991. "On Campus with Camera". Advocate 586 (Sept. 24), pp. 86-87.

MASAYESVA, Jr, Victor (dir). 1992. Imagining Indians. Prod. Victor Masayesva, Jr. 
NIELSEN, Aldon L. 1994. Writing Between the Lines: Race and Intertextuality. Athens, Ga.: U of Georgia P.

PLETT, Heinrich F. (ed.). 1991. Intertextuality. Berlin: Walter de Gruyer.

SPIVAK, Gayatri Chakravorty. 1988. In Other Worlds: Essays in Cultural Politics. NY: Routledge.

STOCKWELL, Anne. 1996. "Cheryl Dunye". Advocate 716. Sept. 17, pp. 69-71.

STUART, Andrea. 1997. "The Watermelon Woman". In Sight and Sound 7.10, 0ct., pp. 63-64.

WEST, Cornel. 1989. "Black Culture and Postmodernism'. In: Remaking History. Ed. Barbara Kruger and Phil Mariani. Seattle: Bay P, pp. 87-96. 